\title{
A Multi-Sided Platform to Activate the Sharing of Digital Labs
}

https://doi.org/10.3991/ijoe.v17i11.25183

\author{
Valentin Kammerlohr ${ }^{1,2(\varpi)}$, Dieter Uckelmann ${ }^{1}$, Jannicke Baalsrud Hauge \\ ${ }^{1}$ Hochschule für Technik Stuttgart, Stuttgart, Germany \\ ${ }^{2}$ Auburn University, Auburn, USA \\ ${ }^{3}$ BIBA - Bremer Institut für Produktion und Logistik GmbH, Bremen, Germany \\ Valentin.Kammerlohr@hft-stuttgart.de
}

\begin{abstract}
This paper presents a business model for digital laboratories (labs) to promote sharing in network organizations. Using information systems design science research methodology, a multi-sided platform is created and evaluated as a sustainable business model. Digital labs complement theoretical concepts in science, technology, engineering, and mathematics (STEM) to promote understanding of concepts, practical knowledge, and experiences. However, these labs are expensive and typically only available to local user groups, and not every university can offer the same or equivalent labs. Many universities are not well prepared to share labs with other institutions or to be part of a network organization. Among the findings are that digital labs are becoming more important, that there is an emerging trend from product- to service-oriented solutions, that a labsharing marketplace should provide targeted offerings for teaching and training, and that industry customers and students are showing interest in digital labs education content. The willingness to pay for students and industry is there, but for students the discussion remains ethical in nature as to who should pay for education. On the other hand, industry customers point out that there is a fear of losing intellectual property and security risks. This paper shows how a sustainable business model for digital labs activates lab sharing. Then universities can offer a better curriculum, instructors have more opportunities to provide a good education, and only then can students have access to more lab environments.
\end{abstract}

Keywords-business model, sharing economy, digital laboratory, multi-sided platform, STEM education

\section{$1 \quad$ Introduction}

New concepts for sharing goods and services between individuals and companies are emerging worldwide [1]. Well-known examples, such as Uber and Airbnb, are seizing new business areas with innovative business models. The sharing economy concept, which was introduced by Weitzman [2], describes behavior where either individuals or organizations make an effort to share existing resources. These include human, material, and non-material resources [3]. Thus, the sharing economy benefits in the form of higher utilization of resources, cost advantages, and access to new knowledge [3]. 
Boons and Bocken [4] categorized the expectations of the sharing economy into ecological sustainability, labor conditions, customer value, social relations, justice, competitiveness, and profitability. In an academic environment, there is great potential to share resources using the sharing economy concept and digitalization technology [5]. Experiments in lab environments with different specializations play an important role in the education of future engineers and scientists [6]. In science, technology, engineering, and mathematics (STEM), the handling of tools, actors, sensors, machines, and robots are taught and learned in labs [7]. Physical labs are used to provide students with hands-on experience and professional techniques and practices. They allow the manipulation of physical components to better understand their constraints in a safe environment. Therefore, universities have their own cost-intensive lab infrastructures with individual learning goals. Unfortunately, labs often have a low utilization rate. This makes labs used for educational purposes good candidates for implementing the concepts of shared knowledge, shared infrastructure, and shared facilities by applying digitalization technology. Therefore, conventional labs are virtualized or made remotely accessible by means of various digitalization technologies. Personal presence in on-site labs is not required, as access is possible via the Internet. Thus, labs can be offered to different user groups. However, there are different solutions for digitalizing real labs to create a shared lab infrastructure [8,9]. The benefits for users include (1) availability: users have access to new resources and digital labs can be used from anywhere at any time, (2) accessibility for disabled people, (3) observability: experiments can be watched by many people, and (4) safety: digital labs can be an alternative to hands-on labs for dangerous experimentation [10-12]. In light of the Covid-19 pandemic, access to lab resources via the Internet is becoming increasingly important. Students are not exposed to danger but can still access learning resources. At first glance, the sharing economy for digital labs offers advantages for suppliers through higher capacity utilization, and the customer side gains access to a wider range of labs.

According to Eikaas et al. [12], a main obstacle for a sustainable business model is "the customers' willingness to buy access to laboratory resources". From a market cost point of view, the question of under what conditions customers prefer to rent labs rather than build them themselves arises. Another question relates to at what point customers would rather form a network with other institutions to gain access to labs. Coase [13] investigated why every needed resource is not purchased through the market using the price mechanism. The reason is the corresponding high costs of organizing and the so-called transaction costs, such as searching costs, contracting costs, and coordination costs $[13,14]$. Consequently, the use of market costs and the forming of an organization has economic benefits. The entrepreneur has to perform the function cheaper than the market transactions he is replacing [13]. The relevance and effect of transaction cost economics were highlighted by three Nobel Prize winners, Ronald Coase (Nobel Memorial Prize in Economic Sciences in 1991) and Oliver Williamson and Elinor Ostrom (Nobel Memorial Prize in Economic Sciences in 2009). With lower transaction costs, it is recommended that labs should be sourced from the market. Today, the Internet and communication technologies are changing the dynamics of transaction costs [15]. As a result, many transaction costs have been significantly reduced and sometimes approach zero $[15,16]$. This justifies the change from traditionally isolated firms to new forms 
of networked organizations. The costs of cooperation and integration with partners (e.g., outsourcing) and customers in business processes (e.g., customization, customer services) are no longer inaccessible [17]. Williamson [18] states that even reputation, trust, and transactional experience can lower the cost of exchanges. Markets have also been revolutionized by the increasing frequency of transactions, the reduction of transaction uncertainty, the reduction of asset specificity, and the large number of interacting parties [14]. Collaboration and exchange requires mutual trust. In the scope of sharing economy, actors need to understand: "(1) states (conditions) of shareable assets in regard to capacity, presence and/or (idle time), capability; (2) previous experience in the sharing of same resource; (3) restrictions and compensation; (4) level of behavioral congruence of actors participating in the sharing; [and] (5) regulatory issues and dispute resolution" [19]. Compared to physical markets, in a digital environment it is possible to set up transparent evaluation systems to address the quality and reliability of stakeholders [20]. This means that labs can be contracted out to the network organization, as long as the necessary trust in the organization is present and it makes sense from an economic point of view (transaction cost).

Having identified the market conditions, a business model for digital labs is required that is tailored to the customers' and providers' demands, while fulfilling the trust in network organizations. Consequently, the first research question (RQ1) is: What are the success criteria for a sustainable business model of digital labs? This question refers to networked organizations and addresses the question of how an ecosystem for digital labs can successfully exist [21]. The second research question deals with the concrete business model of networked organizations. However, the offer for students should be of high quality and comprehensive. In addition, the lab should be operated in a way that guarantees access to the largest possible community. In adapting the business models of the leading providers of the sharing economy, a multi-sided platform would fit the concept. A multi-sided platform is an intermediary economic platform that brings together two or more different but interdependent customer groups; it is used, for example, by Airbnb (landlord and tenant), eBay (buyers and sellers), and Facebook (users, advertisers, and content developers). According to this concept, universities would offer various lab services, and students could meet their needs via appropriate platforms. This results in the second research question (RQ2): What are the functional requirements of a multi-sided platform for digital labs? This paper focuses on answering these two research questions.

\section{Research methodology}

As methodology the paper is following the design science research methodology (DSRM) in information systems of Peffers et a. [22], consisting of six activities. Within the first activity, problem identification and motivation, the problem of underutilization of expensive labs and the potential of digitalization for shared labs for education purpose is addressed. The second activity, define the objectives for a solution, is to establish a sustainable business model that addresses the functional requirements for a multisided platform for digital labs. Third, design and development, is to create a multi-sided 
platform to reach sustainability for a digital lab sharing network. The fourth activity, demonstration, applies the business model as an artifact to a digital lab sharing case study that seeks to provide a marketplace for sharing digital lab resources between suppliers and buyers across institutional boundaries. Evaluation, as the fifth activity, uses a comparable industry example and surveys of industry and students to observe how user groups support the business model. Finally, the problem and its importance is discussed and communicated.

\section{$3 \quad$ Literature review}

The criteria for sustainable business models and multi-sided platforms are described in this section, to address the design and development of the DSRM artifact. The literature review includes an analysis of the definition, framework, and taxonomy of business models. This is followed by an analysis of the core criteria of multi-sided platforms, which is intended to give an indication of the challenges faced to achieve the long-term goal of establishing a sustainable business model for shared lab environments. The literature review is based on Tranfield et al. [23]'s three-step approach: (1) planning a review, (2) conducting a review, and (3) reporting and dissemination. First, the review is planned on the basis of RQ1 and RQ2. Second, the databases for the Journal of Business Models (JOBM) and the special issue Multi-Sided Platforms of The International Journal on Networked Business (vol. 29, no. 4 - Electronic Markets, 2019) have been analyzed. JOBM was chosen because of its focus on business models and the special issue because it addresses multi-sided platforms. Both journals are highranked international academic journals and include meta-reviews on the topics of interest. Data collection took place between December 2019 and February 2020. Altogether, 105 papers from the JOBM database and 10 papers from of the special issue of The International Journal on Networked Business were analyzed using title, keywords, and abstract. Of these papers, 34 were selected for detailed analysis. Five meta-reviews and one trend analysis are included in the literature review. The original works were published between 2013 and 2020. Third, reporting and dissemination are grouped into business model definition (BMD), business model framework (BMF), business model taxonomy (BMT), and multi-sided platforms.

\subsection{Business model definition}

The term business model was first used by Lang in 1947 and has been the subject of debate ever since [24]. There is as yet no consensus regarding a definition. According to Cuc (2020), the most relevant current authors (considering the number of publications and degree of influence) are Zott, Amit, and Chesbrough.

Regarding BMD, BMF, and BMT, the business model literature states the following:

- BMD: authors define business model differently due to a lack of consensus,

- BMF: a template for developing new or documenting existing business models and

- BMT: classify business models according to one or more characteristic criterion 
Is a separate definition for digital lab business models needed? Would it increase sustainability? The necessity and relevance of BMD analysis is well reflected in the work of Jensen [25]. Initially, the concept was used to understand e-businesses [26-28] and to facilitate the use of technology and innovation [29-31]. Market practice was ahead of academic research $[32,33]$, but business models still play an important role for various stakeholders in mobilizing resources in the entrepreneurial process [25]. Literally, doing "business" means carrying out activities or exchanging values, and a "model" is a representation of the reality with different levels of accuracy or detail. A business model is considered "a highly complex entity that can only be represented through abstraction" [32]. Jensen [25] developed a three-level vertical concept of BMD. Level 1 is just the abstract term "business model" for simple and practical use as a keyword with global and local meanings. For level 2, the author defines business models as "a focal firm's core logic for creating, delivering and capturing value within a stakeholder network" [25]. This provides a link between scientific and practical definitions with the domain, features, and structure. Level 3 is grounded on level 2, but the definition depends on the special research topic, with explicit focus on the domain (discourses/research gaps). For level 3, Jensen [25] developed a horizontal view of understanding BMD: (1) the representational view, (2) the functionalist view, (3) the pragmatic view, and (4) the systemic view. Regarding the functionalist view, Jensen [25] recommends that a BMF/patterns should be applied. Thus, the initial question of whether a BMD is necessary at all can be clarified. Based on Jensen's (2018) research, a separate BMD with a focus on digital labs as a research topic (level 3) and a $\mathrm{BMF} /$ pattern representing the functionalist view are required. Several authors combine the creation and capture of customer value within the BMD. Fielt [34] specifies the creation of customer value on one hand and the way to capture customer value (for the creation of business/exchange value) on the other. According to Fielt [34], the definition of business model is "the value logic of an organization in terms of how it creates and captures customer value", focusing on the value logic of an organization. After reviewing the work of Amit and Zott [14], Teece [35], and Chesbrough [30], Yrjölä [36] agrees that a business model describes customers' and firms' value creation. Furthermore, it describes the selection and coordination of activities; a business model is a strategic instrument for innovation and differentiation [36].

A common BMD and general understanding of business models does not exist. This paper treats digital labs as a special research topic, with an explicit focus on the domain; BMD is therefore defined in section 4.2. The next section takes up the recommendation of Jensen [25] and considers the functionalist view of understanding BMD. To represent the functionalist view, there are BMFs that can be used as scaffolding and predefined BMTs. Questions arise as to how the different value propositions for buyers/students and lab suppliers can be highlighted and if these value propositions are related to the sustainability business model. First, the BMFs are examined in detail to determine how business models can be mapped and value propositions identified. Subsequently, which existing BMTs can be used and which functions should be adapted to create a sustainable business model for digital labs is discussed. 


\subsection{Business model frameworks}

The term BMF, which is used differently in the literature, relates to what business models consist of compared to the BMD [34]. According to Osterwalder et al. [37], a BMF consists of building blocks; according to Wirtz et al. [38], it consists of components; according to Morris et al. [39], it consists of questions; and according to Chesbrough and Rosenbloom [31], it consists of functions. What they all have in common is that they attempt to describe business models in more detail using these elements. A BMF not only defines the elements but also represents the relationship/hierarchal structure between the elements. According to Fielt [34], five BMFs are most commonly used. 1) The Business Model Canvas (BMC) by Osterwalder et al. [37] is the best known and most widely used BMF [34, 40, 41]. It is designed to describe, visualize, evaluate, and modify business models. BMC consists of nine elements, where the value proposition connects the supply side with the customers [37]. 2) Weill and Vitale [42] developed the e-business model schematics BMF. Using the elements of Timmers [26], the roles and relationships, major flows of product, information, money, and revenues of the business model are illustrated [34]. 3) Chesbrough and Rosenbloom [31] created the so-called technology-market mediation model, using value proposition, market segment, value chain, cost structure and profit potential, value network, and competitive strategy as BMF elements. 4) The entrepreneur's business model of Morris et al. [39] is iterative using an increasingly specific three-level approach. The foundation level is defining basic components, the proprietary level is creating unique combinations, and the rules level is establishing guiding principles [39]. In each of the three BMF levels, six factors are covered that are related to the offering, market factors, internal capability factors, competitive strategy factors, economic factors and growth/exit factors [39]. 5) The four-box business model of Johnson et al. [29] refers to the customer value proposition, the profit formula, key resources, and key processes. All BMFs use the business model dimensions that cover the core questions about creating and capturing customer value in terms of who, what, why, and how [34]. The BMFs differ but have a very similar and comparable basis. Various authors have dealt with more detailed comparisons of BMFs. An overview can be found in Di Tullio [43]; however, she does not rate the different BMFs. All BMFs have certain advantages and disadvantages.

The authors of this article decided to use Osterwalder's [37] BMC, the most widely used in science and economics. This model is also recommended by the German Ministry for the Founders of New Business. However, the disadvantages of the model mentioned in the literature should be considered. Lund and Nielsen [40] analyzed the advantages and disadvantages of the BMC. They used the BMF to discuss the "Hows" and "Whys" of a company's activities and choices. In this way, the strengths, weaknesses, and potential of a business model become apparent. First, the BMC has limitations in terms of the static nature of the BMF, which inhibit innovation [40]. Second, the BMF reaches its limits in representing the value proposition of all stakeholder when many different companies and individuals form a network in a new business model [40]. To address the first disadvantage, an iteration of the model is required that could be addressed by business model innovation (BMI). BMI is described as a technology, 
process, product, and organizational innovation [30], which is linked with sustainability by Cuc [44]. Zott and Amit [45] describe BMI as the process of adding novelties, linking activities, and changing one or more elements of the business model. Thus, it describes the ongoing process that is required to ensure that a business model remains sustainable. Different variations of BMI can be found in the literature [46, 47]. Cuc and Miina [48] added the strategic perspective of classifying the life cycle phases of a business model to the concept of BMI. Accordingly, a business model develops over several phases with different degrees of innovation. In each phase, a strategic direction is required, such as competitive advantage, improvement or renewal of the business model through innovation, improvement of competitiveness, and an increase in business performance [48]. In the development phase of a business model, the strategic direction and thus the innovation is determined, but in order to achieve long-term sustainability BMI should be taken into account. BMI can be seen as an important tool to continuously monitor whether the value proposition $[25,36]$ is being fulfilled by customers and suppliers. The second disadvantage can be addressed by the Platform Canvas [41]. It is a guide to support the BMC and particularly addresses the platform ecosystem, the participants, and the promotion of innovation. The Platform Canvas [41] uses eight key characteristics of platforms, which are (order does not reflect the popularity): (1) value: value creation potential of the platform, (2) monetizing: capturing the value, (3) producers: side one of the platform, (4) users: side two of the platform, (5) filtering: efficient value exchange to increase matching, (6) governance: control, rules, access control, and trust, (7) resilience: adaptive to change (modular, plug-n-play), and (8) network effect (crucial characteristic): the ability to scale with minimal investment.

For the purpose of the digital lab, the BMC was chosen because it offers the advantages of user friendliness, practical relevance, visualization of content, and is also comparable to other BMFs [34, 40, 49, 50]. However, in order to take into account the disadvantages of the BMC [40] and the platform-specific characteristics, the Platform Canvas [41] must also be applied. In addition, the BMI concept of enriching sustainability can help to continuously adapt the value proposition. Now that a BMF has been selected, whether there are already comparable platform solutions on which we can build can be determined. Is it possible to use similar proven examples (BMT, see section 3.3), such as the prominent market examples mentioned in section 1? Or is it necessary to develop it ourselves? The concept of BMTs is addressed in the following section.

\subsection{Business model taxonomies}

In the literature, there are several approaches for clustering BMTs. Instead of the term taxonomies, analogies, patterns, or classifications are often used in the literature. The basic concept of taxonomy goes back to Plato and Aristotle and relates to evaluating similarities and differences. A BMT is a classification of objects into groups or classes based on their business model similarity [51]. These similarities are interpreted differently by different people, as the analysis shows. Early business model classifications, such as that by Applegate [52], used simple identification categories, such as 
distributor model, portal model, producer model, or infrastructure provider model. Others are based on criteria such as customer profile, market configuration factors $[15,26]$, transaction factors, or marketing strategy [42]. Special digital BMTs are based on business models for the internet/web [26, 53, 54] or atomic e-business models [42]. More recent BMTs are the 19 analogies by Johnson [55], the 55 patterns by Gassmann et al. [47], and the five BMTs of Osterwalder et al. [37].

As an innovation business model for digital labs is to be established, with high quality, comprehensive offers, and availability to the largest possible community, many models mentioned above can be excluded. Lund and Nielsen [56] clustered business models that are capable of unlocking exponentially increasing returns to scale. Learning from this characteristic could help to enable a sustainable lab ecosystem, achieve sustainability, and gain access to a community that enhances the contents. The attributes of scalability described by Lund and Nielsen [56] are that a business model is flexible and the business potential should not be limited by physical or tangible assets, which can also be achieved by digital labs. Nine BMTs are captured as platform concepts that address the demand of labs' suppliers and students, including multi-sided platforms. Compared to multi-sided platforms, however, they do not get to the heart of the matter. The approach of Adaptive [57], is to establish an ecosystem that is based on its own technology landscape. It should be applied to the digital labs, but the technology-driven approach is not at the core of the matter. The concept of a collaboration platform [26] refers to providing a platform with a toolkit and an information environment for cooperation between companies. While promising, the BMT does not address platforms with different user groups, as we would have with digital labs. The facilitation of transactions based on the brokerage taxonomy [55] is a task but does not correspond to the core business of the marketplace. The multi-sided platform for digital labs reduces, transaction costs, is tailored to the demands of customers and providers, responds to their independent value propositions, lives through the community, promotes high quality, and is considered a market-disruptive model within the sharing economy. In addition, in the digital economy, multi-sided platforms are a strong BMT due to their adaptability, ability to deal with complexity, rapid scale-up due to the network effect and value capture [16]. In order to learn from the model properties, specifics and limitations of the business model are elaborated in the following section to show the functionalist view of multi-sided platforms for digital labs.

\subsection{Multi-sided platforms}

Apple, Airbnb, eBay, Uber and Google are successful examples of organizations that have managed to establish an ecosystem using a multi-sided platform. Several definitions of a multi-sided platform can be found in the literature [58-60]. The definition of Osterwalder [37] is commonly used:

"Multi-sided platforms bring together two or more distinct but interdependent groups of customers. Such platforms are of value to one group of customers only if the other groups of customers are also present. The platform creates value by facilitating interactions between the different groups. A multi-sided platform grows in value to the extent that it attracts more users, a phenomenon known as the network effect." 
In short, the core elements are hubs or intermediaries for the exchange of values between interested parties and suppliers from two or more markets [61]. In the case of a digital lab network, the interested party comprises, for example, students (collectively called the buyer) and the suppliers are universities (or providers, collectively called the supplier); both sides can be expanded to include other stakeholders. The peer-to-peer marketplace is the actual platform on which joint exchange and coordination service take place. The marketplace aims to bring together the supplier of a given resource with the party (two or more) interested in using that resource; this is known as matching [62]. The main difference is that the marketplace does not acquire ownership, of the traded resource and therefore does not influence the way it is presented or the price. The conditions for sharing are therefore directly controlled by the supplier and the buyer. The digital lab supplier must therefore keep their offers and prices attractive in order to attract and keep the buyer. Commercial marketplaces all host a platform or online marketplace through which matching takes place; it can be demand-driven, supply-driven, or a combination of both [62]. More users increase the value of the marketplace, the so-called network effect [16]. Eisenmann [63] distinguishes between two types of network effects, same-side (or direct) effects and cross-side (or indirect) effects, where the value of the marketplace is measured based on the number of sameside or cross-side participants. The cross-side network effect is measured between the lab supplier and the buyer side.

If the marketplace has no influence on the offers, how can it generate revenue? The marketplace can use two forms of income [64], transaction-based commissions and non-transaction-based or transaction-independent commissions [63]. Transactionbased commission is based on the successful matching of supplier and buyer; a service fee is charged on the matched price/fees. The non-transaction-based commission is not related to the matching; income is generated by the sale of advertising space, membership fees, subscription options, or registration fees for using the marketplace. Both commissions are subject to risks; in the case of the transaction-based commission, the added value of the marketplace can be questioned for each transaction. The non-transactionbased commission can be an initial obstacle and may have a frightening effect. The marketplace owner should find a commission system, taking into account the impact on growth and willingness to pay. In most cases, the networks have a subsidy and a money side (or charge side). If the marketplace can reach enough users on the subsidy side, the users on the money side will pay to reach them [63].

According to Henseling et al. [65], the challenges of a multi-sided platform are: (1) strengthening user trust, (2) further development of marketplace offerings, and (3) acquisition of new user groups. Loss of trust in the network organization would result in the collapse of the network effect. If a digital lab is booked but not available in the expected condition, the buyer has no benefit at all. However, if the buyer of the lab does not handle the situation carefully, the suppliers stay away. How trust can be strengthened is the greatest challenge of the sharing economy and has been discussed by many authors from different disciplines $[3,19,64,66]$. The challenges are also described in Abdelkafi et al. [16], as shown in Fig. 1, whereby they are grouped according to the marketplace life cycle phases. A marketplace life cycle consists of three phases [16, 67]: (1) design: technological architecture and innovation of the platform (software and 
hardware), (2) dynamics: evolution of the platform and ecosystem by attracting users and adding new functionalities, and (3) performance: scaling, growing, and succeeding in competition. This approach is somewhat similar to BMI, where the business model and tasks are adapted to the current phases and associated challenges.

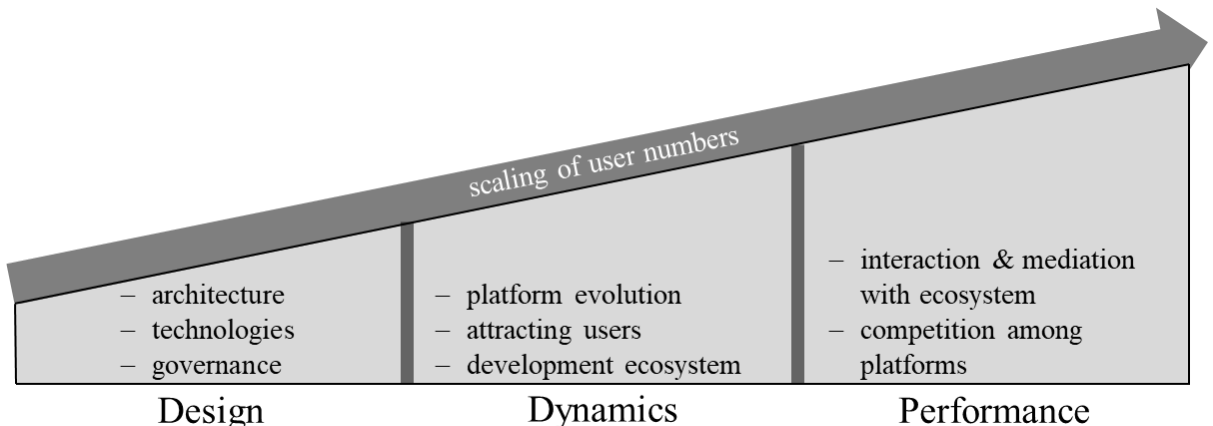

Fig. 1. Challenges of multi-sided platforms within the life cycle phases, based on Otto and Jarke [67] and Abdelkafi et al. [16]

In summary, multi-sided platforms have some specific features that should be considered as a business model. First, the two parties (buyer and supplier) must be addressed individually. Second, the type of commission to be applied has to be worked out, which is directly related to the network effect by reaching as many cross-side participants as possible. This is also where the core challenge begins; the marketplace must create trust among the parties in the network organization, and the marketplace offering should be further expanded.

\subsection{Findings of the literature review}

The literature review based on JOBM and the special issue could provide comprehensive insights into the current research on business models and are critical to the design and development of the DSRM artifact. The sources have proven to be valuable due to their consistency and thoroughness. Before the theoretical construct is applied to digital labs, it is summarized below in light of the research questions.

Modern definitions of sustainability refer to ecological, economic and social aspects $[68,69]$. With regard to digital labs, it is essential to note that economic innovations should be integrated into the business model and that these must also increasingly fulfil ecological and social goals. The intention is that through the right choice and application of business model, sustainability can be achieved. Three elements are necessary to successfully implement a business model: (1) a BMD, (2) the use of a BMF, and (3) the application of a BMT. (1) A BMD helps to mobilize resources in the entrepreneurial process. The BMD must not only show the value proposition for the organization but also for its customer groups. (2) The application of a BMF shows the functionalist view, the advantages and disadvantages, and the correlations and dependencies of a business model in discussions with stakeholders. Various models exist, and the BMC of 
Osterwalder et al. [37] has been chosen as a useful one for the digital lab case. However, the BMC also has pitfalls, which should be specifically addressed, for example, with the help of the Platform Canvas [41] and BMI. The Platform Canvas can be used as a supplement in the successful implementation of platform-related business models, and BMI can be used to achieve economic sustainability within the life cycle phases. (3) By applying a BMT, special characteristics of a business model can be classified. In our case, the scalability of the business model can be achieved by the new distribution channels, liberation from traditional capacity constraints, the outsourcing of investments, the use of partners who work for free, and the implementation of platform models [56].

The multi-sided platform is convincing due to the approach of the two shared user groups, whereby the marketplace itself offers added value by facilitating interactions between the different groups. In addition, the multi-sided platform lowers transaction costs, is tailored to the demands of the buyer and the supplier, responds to their independent value propositions, lives through the community, promotes high quality, and is considered a market- disruptive model within the sharing economy. In order for the marketplace provider to be successful, the highest possible cross-side network effect must be created. This can be achieved by an attractive commission system, trust within the network organization and a service framework for the supplier and the buyer. Trust in the network organization is of utmost importance. Marketplace providers, the lab supplier, and the buyer should have a strong trust relationship because they need to rely on each other. A lack of trust can have both organizational and social consequences for the individual and the group. Furthermore, a continuous iteration process maintains the attractiveness of the platform. Similar to the BMI principle, the development of the marketplace must be reinvented, and the actual way in which value is created and captured has to be transformed in the three life cycle phases of the multi-sided platform. The main challenges here are the strengthening of user trust, the development of offerings, and the acquisition of new user groups to scale the user numbers.

The demonstration of the theoretical construct is divided into two steps. First, the general feasibility of a multi-sided platform for digital labs is demonstrated using the Open Digital Lab for You (DigiLab4U) research project as a case study. This allows on the one hand to assess the general feasibility and on the other hand to make the value dimension of the actors more tangible. The results of the case study and the literature review will be used to outline a concept for the multi-sided platform. In a second step, the functional perspective of the business model for digital labs is developed by applying the BMC and further working out the characteristics using the Platform Canvas. The BMC separately represents the two value dimensions of the supplier side and the buyer side. Afterwards, the business model is evaluated based on the two actors. For this, the business model transformation of the supplier side is evaluated and the intention of the buyer side to use labs on the basis of industrial customers and students is surveyed. 


\section{$4 \quad$ Multi-sided platform for digital labs}

In this section, as the fourth DSRM activity demonstrates the artifact, a business model for a multi-sided platform for digital labs is developed. The feasibility of the theoretical concept is therefore tested in the context of a case study for digital labs in a shared environment. Next, the business model for digital labs artifact is defined and the concept outlined. As an artifact for problem solving, the BMC is developed for elaborating the functional perspectives and Platform Canvas is applied for ensuring the sustainability of the platform ecosystem.

\subsection{Feasibility check using DigiLab4U case study}

With the help of the research project DigiLab4U, it will be demonstrated that the multi-sided platform is suitable as a BMT and can support the sustainability of the network. DigiLab4U connects organizations teaching and researching in the STEM area. The common basis of the project members, four German academic institutions and one Italian one, consists of practical education, training, and research in physical labs. The project intends to offer a digital lab environment that enables the networking of real and virtual lab facilities across locations within the network organization. The networking of the labs is intended to save human and financial resources and to increase the number of users previously restricted to their own institution. For example, students in Stuttgart should be able to access labs in Bremen or Parma and vice versa. Furthermore, the digital labs are to be integrated into digital teaching content via a platform and supplemented with the latest educational methods in engineering related to education 4.0. In order to reach a larger number of labs and students in the network, eight additional external labs will be directly supported by a financial incentive for the mobilized in the hope that more labs will subsequently join the network indirectly.

Moving DigiLab4U towards a multi-sided platform. There are several steps to be considered when moving the DigiLab4U research project towards a multi-sided platform. The closed circle of the network organization must be opened for further suppliers and buyers of digital lab offerings to support the cross-side network effect. The marketplace would consist of the digital labs on one side and the buyers accessing the labs on the other side, linked by the marketplace for the purpose of matching. The differentiation of the stakeholders by (lab) supplier and buyer side is shown in Table 1.

Table 1. DigiLab4U stakeholders in the multi-sided platform business model

\begin{tabular}{|l|c|c|c|}
\hline Stakeholder & Supplier Side & Marketplace & Buyer Side \\
\hline DigiLab4U & & $\times$ & \\
\hline Universities & $\times$ & & $\times$ \\
\hline Research institutions & $\times$ & & $\times$ \\
\hline Industry & $\times$ & & $\times$ \\
\hline Students & $\times$ & & $\times$ \\
\hline Professors/lecturers & & & $\times$ \\
\hline Researchers & & & $\times$ \\
\hline
\end{tabular}


The supplier side could consist of various labs of universities, research institutions, industry, and professors/lecturers. The added values of the supplier side are an additional source of income and access to the professional community [3]. There are several examples of digital labs that could be potential suppliers in the marketplace, such as TU Dortmund University (running material characterization tests remotely with a robot arm), TU Braunschweig (operating a teaching and learning factory for Energy and Resource Efficiency, Digitalization and Urban Factories), or the Digital Capability Center Aachen (learning factory for the I4.0 value chain) [70]. There would be a growth opportunity for the network effect, as almost every physical lab could be retrofitted with digitalization technologies. The buyer side would consist of students (bachelor to doctorate levels), researchers, professors/lecturers, universities, industrial companies, and research institutions. Benefits for buyers by using the marketplace would be access to unique labs independent of time and place and access to more digital education content. The current market segmentation into STEM areas and buyer groups (bachelor to doctorate levels) restricts the network and requires different lab characteristics and education levels, but the restriction also has advantages for forming the network community. Furthermore, the added value of the marketplace must be visible for both sides. The basis for this could be a service framework for the technical, didactic, and organizational landscape forming an ecosystem around the marketplace. Next, the commission system is a fundamental choice, and both transaction-based and non-transaction-based commissions have advantages and disadvantages. However, the buyers accessing the labs will be the paying/buying network side, unless the revenue is generated externally, for example, through advertising, which is not initially assumed.

Fig. 2 illustrates the DigiLab4U concept for multi-sided platforms. The supplier (blue) is sharing STEM labs with the buyers (green) via the DigiLab4U marketplace (grey), taking into account the service framework. A fee-based commission system is used for the purpose of explaining the concept.

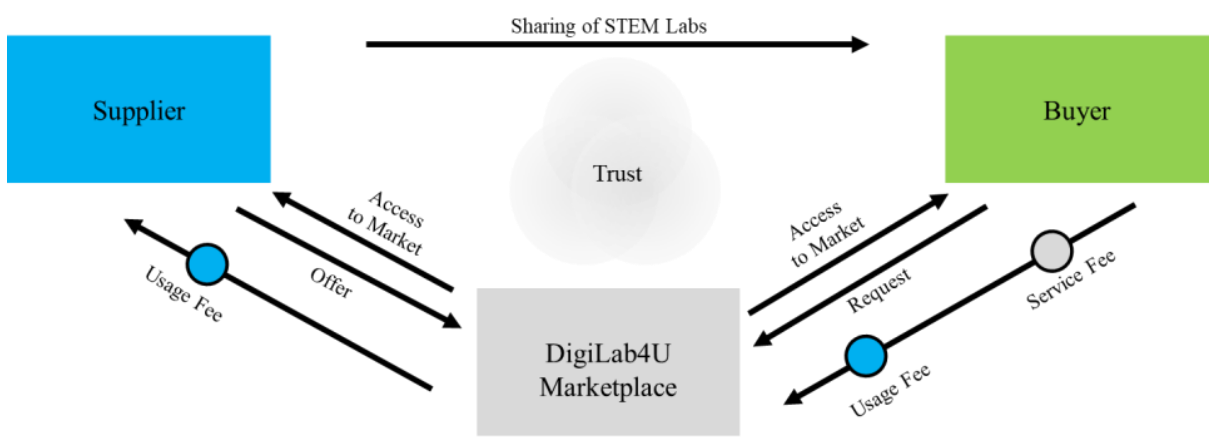

Fig. 2. DigiLab4U concept of multi-side platform business model, based on Singh and Singh [71]

The feasibility of using the multi-sided platform as a business model for digital labs could be proven in general by the DigiLab4U case study. The sustainability of the network is supported by the BMT, as the supplier side is interested in placing an attractive 
offer to attract many customers, and the service framework of the marketplace can support this. Open questions remain, namely, which relationship/hierarchical structure exists between the business model elements, which value dimension (like service framework) the marketplace offers, and how the commission system is structured. Because the general feasibility has been proven, the business model for digital labs can now be created on the basis of the theoretical construct.

\subsection{Multi-sided platform for a digital lab marketplace}

This section aims to establish a multi-sided platform business model for digital labs by defining the model, elaborating the characteristics using Platform Canvas, and creating the functional perspective using the BMC.

Business model definition. Multi-sided platform for a digital lab marketplace is defined as a sustainable digital lab ecosystem that provides a marketplace for digital STEM education and research. The marketplace facilitates the lab supplier to achieve additional revenue and the lab buyer to maximize the education and research process.

The BMD is specific for the digital lab research topic $[25,34,36]$ and describes how the digital lab business model creates, delivers, and captures the value logic. It consists of several elements: (1) Sustainable digital lab ecosystem: this distinguishes the marketplace from a purely profit-oriented model and concerns sustainability in the sense of network organization. (2) Marketplace for digital STEM education and research: this element addresses the mission of the business model. The model should act as a platform in the specified customer segment, STEM education and research. (3) Marketplace facilitates the lab supplier and the buyer: this describes the value proposition of the marketplace. The marketplace facilitates matching for the lab supplier and the buyer. (4) Lab supplier to achieve additional revenue: the first stakeholder group comprises the lab suppliers, who have a higher utilization and thus a further source of revenue by sharing the labs. (5) Lab buyers to maximize the education and research process: the value for the second stakeholder group is the education and research content based on the digital labs. By bringing together the marketplace, the lab supplier, and the buyer, the network is expected to grow. Next, the technical construct of the business model is created by extending the BMC with the Platform Canvas.

Business Model Canvas. The BMC with the nine elements is shown in Fig. 3. The customer segment buyer with the value proposition and money flow is highlighted in green, the customer segment lab supplier with the value proposition and revenue stream is highlighted in blue, and the marketplace elements are highlighted in grey. The individual elements and their interactions are explained below. 


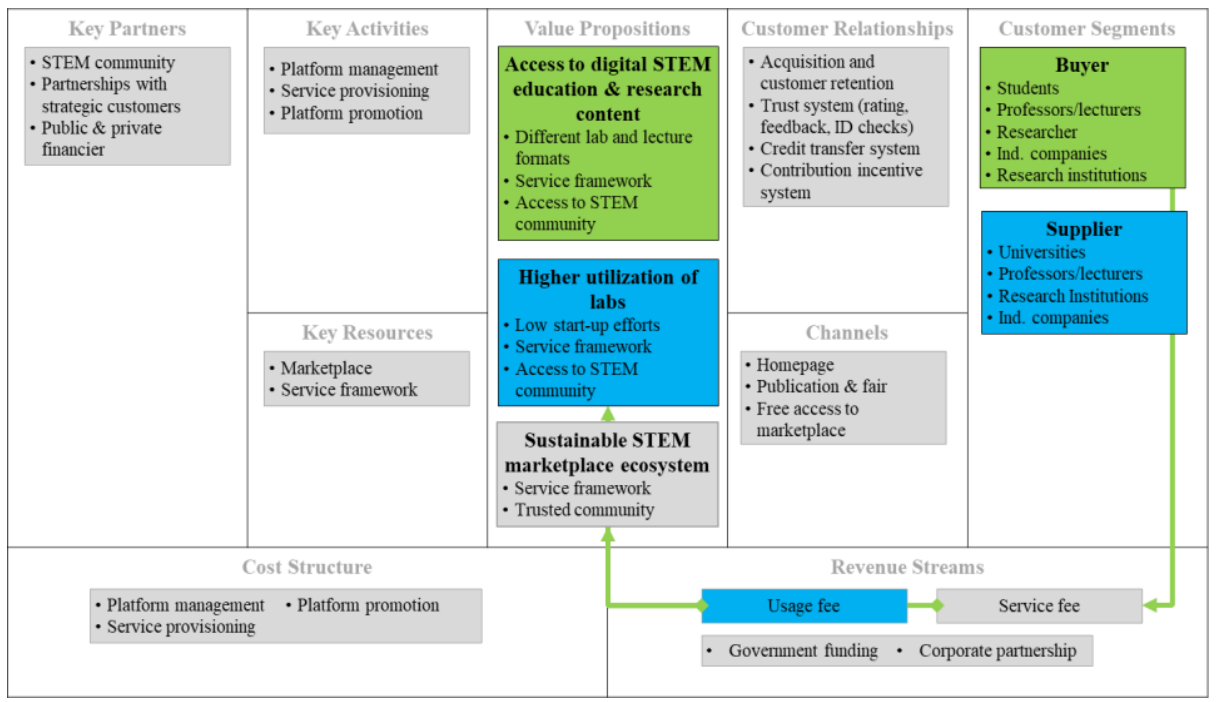

Fig. 3. Multi-sided platform as business model for digital labs, using the BMC of Osterwalder et al. [37]

- Value Proposition. The value proposition is prepared with the BMC especially for buyers (green), suppliers (blue) and the marketplace (grey). There is a financial benefit for buyers in gaining access to lab facilities and learning content at a lower price than if they set up the same service on their own premises, including the cost of hardware, software and labor. They also get flexible access to STEM digital education and research content provided by suppliers and marketplaces. Different lab and lecture formats can be utilized without the need to build up their own extensive knowledge in areas of education 4.0. The service framework supports the transactions and makes them as easy as possible for the customer. The STEM community also provides access to peers for research or education. The main motivation of the supplier to develop a revenue stream through the lab is indicated by the green arrow. The value proposition for the supplier includes the unneeded customer acquisition cost, co-financing of existing lab infrastructures, assisting in the remote accessibility of lab equipment for their own students, access to community and enhancing their reputation in research and education. In addition, access to the STEM community is highly valued, especially for companies and public institutions, in order to establish new contacts. The marketplace brings the two customer segments together through the sustainable STEM marketplace ecosystem, which is maintained by a service framework and a trusted community and increases the goal of an overarching network effect.

- Customer Segments. Besides the buyer and supplier segmentation, STEM is addressed as a special community. Buyers can be institutional (universities, companies, research institutes) or individual (students, professors/lecturers, researchers) and may require different agreements/contracts. The green arrow indicates that the 
money flow is coming from buyers. Because suppliers, such as universities or companies, can also become buyers, a compensation scheme is conceivable. In return, a supplier of one lab can use another lab.

- Revenue Streams. The main source of revenue will come from the buyers, who will pay a usage fee for the use of the labs. As the green arrow shows, the usage fee goes to the supplier of the used labs and the service fee goes to the marketplace as service fee. Other sources of income for the marketplace could be government funding or corporate partnerships, as digitalization in research and teaching is a funding issue.

- Customer Relationship. Acquisition and customer retention is the primary task and is supported by the trust system. A trustworthy marketplace is the key to successfor the supplier in that sensitive labs are used correctly and for the buyer who uses the lab in the expected way. A transaction rating, a possibility of feedback and an ID check should support this. A credit transfer system and a contribution incentive system could also increase the activity of the community.

- Channels. Access to the marketplace is provided free of charge, which activates customers and has a positive effect on the network effect. This is supported by different channels for addressing customers. Individuals are addressed through the homepage, trade fairs and scientific publications; for institutions, personal contact may also be required.

- Key Partners. Strategic partnerships with professors/lectures, researchers, industrial companies, universities and research institutions can help to win new customers, expand educational content and extend and improve the service framework. Lab availability is a key quality criterion for online labs; therefore, strategic long-term partnerships are preferred. However, professors/lecturers can leave a university or change their job. Therefore, a contract should support a structured handover procedure for internal or external alternative supporters. Thus, the partnerships can also influence the sustainability of the platform. The financiers provide public and private funding and donation programs.

- Key Activities. Platform management, service delivery and platform promotion are the key activities that should be performed by the marketplace. The further development and operation of the platform expands the standardized service framework and enables quick and easy access for supplier labs and buyers.

- Key Resources. The resources are the marketplace and the service framework. The community, user and research data and the trust system could also be key resources, but as they are not physical assets this is not directly mentioned.

- Cost Structure. The costs of the marketplace are determined by the operation of the infrastructure, the development of the marketplace, the acquisition of the community, the promotion of the marketplace and the services offered. Some of the costs can be directly allocated to the transaction, which creates transparency about the cost drivers. 
Platform Canvas. The Platform Canvas supplements the BMC by addressing key characteristics of the digital lab platform ecosystem.

- Value. A sustainable STEM platform ecosystem describes the added value of the marketplace, which consists of three components-STEM as a delimited market segment, an ecosystem as service framework surrounding the marketplace and a sustainable marketplace consisting of two participants supported by a trust system.

- Monetizing / Value capture. The main revenue stream relies on transaction-based commissions [64]. A transaction fee for matching a supplier and a buyer (money side) is charged. The lab supplier offers a self-determined price for a buyer to use the lab, and the marketplace charges a service fee on the transaction. The market balance promotes sustainability and high-quality offers. The service fee should be adapted to the diversity of the service framework (continuous development process or BMI) and can be adjusted for strategic partners.

- Value Producers. The producers of value are the lab suppliers, such as universities, research institutions and industrial companies, who are seeking more intensive use and thus additional income for the labs [12]. For the lab suppliers, the value proposition consists of offering their lab services to an existing user base and handling the transaction via the marketplace. Suppliers are motivated to participate in the market because of lower customer acquisition costs, participation in new markets, lower costs for advertising and brand awareness, the service framework, mutual trust, and direct access to the community. In this way, the marketplace reduces the frictional losses in order processing through billing and booking systems; the effort put into didactic-technical preparation of the contents enables tailor-made offers and creates trust among the market participants. As a result, the effort for the lab suppliers is low due to the standardization of the marketplace, while the learning success for the buyers is high. In line with the transaction costs, it can be assumed that suppliers prefer integration into an existing marketplace ecosystem rather than creating their own solution [15].

- Value Users. Buyers get flexible access to digital STEM labs and learning content regardless of time and place. The buyers are categorized into three different groups for teaching, training, or research. Professors and lecturers use the marketplace for teaching purposes. A modular teaching offering with practical labs addresses their educational needs. Bachelor's or Master's students, private individuals, or industrial companies can use the marketplace for learning purposes. Advantages for these users are validated, and practical learning contents, structured education paths, innovative teaching methods according to education 4.0, certifications (e.g. badges), and the digitalized remote and therefore flexible access to educational content are provided by the marketplace. Use of the marketplace may be based on intrinsic or extrinsic motivation; for example, students are often obliged to follow the technical conditions of a lecture in a curriculum. Besides supporting learning and teaching purposes, the labs can also be used for research purposes. Researchers, companies, and research institutions use the labs to pursue technical STEM topics and gain access to research data; this group stimulates the sustainability and innovation of the labs and the marketplace. 
- Filters. Market segmentation is considered the key to success in competitive markets. A possible segmentation towards a lab community domain can address current educational and research topics such as STEM or IoT/I4.0 educational programs. It addresses different groups (suppliers/buyers) with the same needs and wants. Therefore, forming a community is easier than in a non-segmented market. A customerspecific search, filter and matching function makes the marketplace accessible through a) customer data such as language, degree, course of studies, semester, university, recommendations, learning paths based on badges, certifications, and mentor/mentee promotion and b) lab data such as lab subject domain, type, language, or education level.

- Governance. The marketplace provides a service framework and a trust model for lowering the barriers to entering the marketplace. The service framework consists of technical, didactic, and organizational components that form an ecosystem around the marketplace, for example, standardized architecture, interfaces to third-party systems such as learning management systems, security and safety mechanisms, data protection and privacy, backup systems, data management, booking and accounting tools, order processing, trust systems, virtualization systems such as virtual and augmented reality (VR/AR), learning analytics, and serious gaming. The components are to be understood as an initial collection of ideas and should be adapted to the current needs of the customer as a continuous development process according to BMI. Current trust mechanisms of digital platforms use the 1-5-star rating system. The authors research a much more precise trust model that visualizes the current trust behavior in a shared environment [19]. Because the current relationship is dynamic due to the impact of external events, a transaction-based operationalization is pursued. The model should reflect: "(1) states (conditions) of shareable assets in regard to capacity, presence and/or (idle time), capability; (2) previous experience in the sharing of same resource; (3) restrictions and compensation; (4) level of behavioral congruence of actors participating in the sharing; (5) regulatory issues and dispute resolution" [19]. The transparent system can be operationalized over time and enriched with additional components.

- Resilience. A technical, organizational and financial distinction for resilience is made. The use of a standardized platform architecture and standardized interfaces increases the technical resilience. From an organizational point of view, there could be changes of lab personnel; however, an overall agreement with the organizations can prevent this. Financial resilience must be achieved through a sustainable business model, which cannot be achieved with temporary resources alone.

- Network effects. The network is stimulated by subsidies and a money side effect. A registration option that is free of charge for both sides allows scaling with minimal investment. The subsidy side is represented by the lab supplier, who get access to the service frameworks and thus creates the highest quality lecture and lab content. The money side is represented by the buyer, who pay for access to lecture and lab content. Strategic partnerships -for example, with universities that offer labs, students, and marketplace content-lower the access barriers to the platform for members of these partner universities. It is important to quickly reach a critical mass of 
suppliers and buyers, which could be achieved by first-mover rewards. Temporary promotions or test access could increase the effect in the short term.

\section{$5 \quad$ Evaluation}

In this chapter, three user group evaluations are used to assess how effective the artifact is based on the sustainability and functionality requirements of the developed business model. First, the experience from the serious game industry, which has undergone a comparable transformation of products to service-oriented products, was compared with that of the lab supplier side. Second, industry companies were interviewed in semi-structured survey about their intentions to use a platform to access digital labs. Finally, the intentions of students to use online labs were also collected using a semistructured survey.

Experiences from the serious game industry should help to better understand the challenges of the supplier side. The serious game industry faces similar challenges, according to a report by the Game and Learning Alliance (GALA) which we saw at labs for education [72]. Serious game business models and strategies are often characterized by a niche strategy, are highly individualized, are cost-intensive, are subject to low reusability, and the funding scheme shows a high level of involvement from government or non-profit organizations [72]. Similar to digital labs, market expansion can be achieved either by increasing the number of potential customers or by finding radical approaches to reduce costs and generate new revenues, otherwise they will remain in quality niche markets. A transition to a service-oriented business model, shows on the basis of two examples how thereby new markets are entered [72]. Here, the tangible product is not the unique selling point, but a range of (customizable) services. The end user gains access to the product via the Internet as a sales channel as part of a service provided by experts. The providers thus achieve that the business model used is dynamic, responsive and adaptable to new trends. For sharing digital labs towards a service-oriented business model, the reduced product orientation means that generic labs should be adapted to the individual needs of customers. Here, a key to success lies in the early discovery of market changes such as STEM or IoT/I4.0 educational programs, the focus on reusability and interoperability of teaching and learning content, and responding to customer needs in terms of service design (value proposition) such as with a service framework.

To understand the industry side of the multi-sided platform, a semi-structured online survey (because of Covid-19 pandemic) was conducted with qualitative and quantitative questions. The first section of the survey collected data regarding the respondents' affiliation, which was collected exclusively for quantitative analysis. The second section asked whether or not respondents had ever used digital labs. Based on their responses, two patterns were defined, section 3 with questions for respondents who have already used digital labs and section 4 with questions for inexperienced users. In both sections, the questions relate to (1) the type of lab used or likely to be used, (2) the quality of the service offered or expected, (3) benefits and knowledge acquired or expected, (4) whether there was a platform managing access to content or whether it was 
intended to improve the quality of the service, finally (5) how much it cost to use the lab and related services (and relative perceptions in spending), or whether the cost was intended to be reasonable. Twenty-one entrepreneurs and practitioners (18 managers or chief officers of technical divisions) from the northern Italian area participated in the survey, 16 of whom work in the manufacturing sector and 5 in the tertiary services sector. The results show that of the participants, no one has used a digital lab yet. However, $67 \%$ say they view digital labs as useful for continuously improving business practices or the portfolio of offerings to customers. 57 percent of respondents expect digital labs to allow them to conduct tests on material they would not otherwise have access to. $57 \%$ of respondents cannot assess what added value a marketplace can bring to the player. However, $48 \%$ do not reject the possibility of a third-party provider managing the service framework, and the main reason is the trustworthiness of the system $(48 \%)$. Finally, regarding the financial sustainability of digital labs and marketplaces, $67 \%$ of respondents believe that they can be considered as service offerings for customers to pay for. Pay-per-use is the preferred payment typology (67\%), while $19 \%$ of respondents link the payment typology to the service provided. Further results emerged from the quantitative perspective. The industrial customers repeatedly made reference to various cloud software offerings which, in their view, are comparable solutions and could therefore be easily integrated into everyday business. Of interest here are simulation software or special technology such as AR systems, digital twins or artificial intelligence, which represent a greater challenge for small and medium-sized companies, for example. In general, there is no question about the benefits, as there are high hopes for digital labs (easy access to resources and experiments, knowledge and experience, easy to use, limiting the company's investments in specific simulation tools, save time and possibly money). Concerns about their use have repeatedly been data security and the outflow of core knowledge from the company. They expect a marketplace provider to make the lab easy to use, to offer support, to speed up processes and to make labs findable as services ("market service should focus on effectiveness more than efficiency").

Finally, students' intentions to use digital labs were surveyed. A semi-structured online survey with qualitative and quantitative questions was conducted in February through April 2021. Respondents were asked to answer the questionnaire qualitatively and were additionally free to answer questions freely. The survey was divided into four sections as we have seen in the survey of industry companies. The first section was used to collect the data regarding the respondents' affiliation, these were analyzed only qualitatively. The second section was used to find out whether or not the students already had experience with digital labs. Based on this, the survey was divided into section 3, for the students who have previous experience with digital labs, and section 4, for those who have no previous experience. Section 3 asked how students became aware of digital labs, what lab typology was used and how lab access was, problems encountered during lab use, whether they benefited from the lab and were satisfied. Finally, the survey asked who should pay to use such labs, what payment method was used, and how much students would be willing to pay for a lab supplier in the field of study that would enhance the learning experience. In section 4, lab typology interest was first 
asked followed by, factors that discourage use and what requirements users have, meaningfulness within the field of study, and general potential of digital labs. Finally, this area also asked who should pay for the use of such labs, which payment method is preferred, and how much students are willing to pay for a lab supplier in the field of study that would improve the learning experience. The survey was not geographically limited, but German and Italian students were actively contacted. 93 students participated in the survey ( $43 \%$ female), of which $85 \%$ were between 20 and 25 years old and $13 \%$ between 25 and 35 years old. $4 \%$ of the students achieved a Master's degree, $20 \%$ a Bachelor's degree and 74\% a secondary school degree, of which 50\% were in the field of professions and applied sciences, 35\% in formal sciences, $9 \%$ in humanities and social science and $6 \%$ in natural sciences. $55 \%$ of the students were already aware of digital labs before our survey, and $12 \%$ of them used digital labs in their academic curriculum/practices. The results from the section of students who already used digital labs (section 3) are derived from 11 responses. This became aware of the labs mainly through digital channels, which is in line with the findings of the pre-evaluation. Two of the participants already use a marketplace platform to access the digital labs, 6 use access through the university and/or an associated learning management program, and the rest use direct access. Of these, the majority had a problem accessing or using the lab. All students derived some benefit from using the labs and platform. Both the access, problems, and high benefits give a positive indication of the willingness, potential, and usage of a marketplace platform for digital labs. Positively surprising was the feedback from the experienced students about the amount they are willing to pay for a digital lab supplier. Under the clear condition of added value (accessibility and content) for the learning experience, only one student was not willing to pay for the usage, but willing indirectly through tuition fees. All others were willing to pay between $5 €$ and $50 €$ monthly or $10 €$ to $100 €$ one time. One of the participants was even experienced and had already paid $20 €$ for the use of a digital lab. The results from the area of students who have not used a digital lab (section 4) are derived from 82 responses. As expectations of the digital labs, they name valuable contents $(70 \%)$, easiness of use (67\%), affordability (48\%), materials and equipment not otherwise accessible $(59 \%)$ and customer care (39\%). This describes the requirements or value proposition needed for a successful marketplace platform. In general, 35\% find digital labs very helpful to get new information and knowledge and 56\% find them helpful, which confirms the demand for digital labs. The feedback on who should pay for the lab use is diverse and controversial. The majority expects universities to pay (54\%), followed by the government $(35 \%)$, students $(6 \%)$, and the rest from a mix. As a payment method, the majority expects a subscription model. Finally, feedback from students on the amount they are willing to pay for a digital lab supplier. Again, the expected benefit and the needed value proposition is always brought up. There must be a "true value", it depends on the "type of service", it "depends on the content and the amount of service". The students are willing to pay between $10 €$ and $50 €$ monthly or $5 €$ to $100 €$ one time, with the majority at about $10 €$ monthly. Compared to the students who already have experience with the digital labs, it is noticeable that those who have no experience find it difficult to assess the benefits ( "I don't know" or "I have not any method of comparison"). Or it should be a mix between university, faculty, and tuition. One feedback states "it 
should be part of the educational offer of a university" another it should be a "modest amount, not excessive", both once again focusing on the educational industry we are in and its expectations such as fairness towards a professional online marketplace.

\section{Discussion}

The established business model for digital labs, as DSRM artifact, is discussed in this section in relation to the research questions, taking into account the literature, the case study, and the evaluation results. The theoretical analysis of the business model has shown that there is still considerable controversy as the core elements are still being investigated. By applying the theoretical construct, it is possible to summarize which functional requirements of the business model are particularly important. The BMD could provide good insight into the components and how value is created, delivered, and captured. The visualization and interaction that was missing could be well supplemented by the BMC. In addition, the Platform Canvas helped to highlight the relationships, functions, and issues between the elements. In particular, it identified the individual value contribution of the actors and the ways to monetize it. Thus, elements such as the value proposition are repeated, but support the holistic and structured technical design of the model. An unsolved problem is that the market situation is dynamic and may necessitate permanent adjustments to the model. The BMC is by nature a static model, which does not mean that it should not be updated regularly and that there are no risks in implementing it. Therefore, as an organizational measure, BMI should regularly question how value is created, delivered, and captured in the marketplace. Subsequent evaluation has also revealed additional insights into the functional requirements. Customers expect valuable content, ease of use, affordable service, access to otherwise inaccessible materials and equipment, and customer support. Simply put, the benefits of a platform must be proven over direct access, and the actual benefits are the selling point. In addition, the system and platform must be trustworthy. This point relates to both the platform's functional and success criteria. However, it is also clear that the two user groups, industry and students, have somewhat different requirements. For example, integration into the corporate structure, data security or the retention of intellectual property are of high importance. For students, the added value must be evident in comparison to or in addition to the regular lecture.

Key answers to the success criteria for a sustainable business model of digital labs were found during the literature review, and further insights were gained through the practical application towards digital labs and evaluation. Sustainable business models are a controversial topic of research and the definition changes according to the person. Modern abstractions refer to ecological, economic, and social aspects. In the context of this work, the authors have considered sustainability in the sense of modern economics as the life span of products, whereby the social and ecological aspects also gain importance here. A multi-sided platform as a marketplace for digital labs reduces the transaction costs to a reasonable minimum. The scalable requirements of a multi-sided platform could be met by digital labs and fit to the scalable BMT. The cross-side networking effect is fulfilled by the lab supplier and buyer sides. Three challenges were 
identified-development of offerings, acquisition of new user groups, and strengthening user trust. The multi-sided platform helped to respond to the specific demands of suppliers and buyers and provided insight into the necessary trust relationship the network organization requires. The multi-sided platform as a business model has helped to create sustainability and high quality through market balance; the supplier is motivated to offer the highest possible quality. In addition, the directly addressed stakeholder value proposition, the cross-side network effect, the trusted community, the service framework, and the continuous review process based on BMI could be seen as key components of a successful and sustainable ecosystem. Accordingly, a business model develops over several phases with different degrees of innovation. In each phase, strategic direction is required, such as competitive advantage, improvement, or renewal of the business model through innovation, improvement of competitiveness, and an increase in business performance [48]. This need also became clear in the evaluation; the business model should be dynamic, responsive and adaptable to new trends. The experience from the Serious Game also showed that the number of customers' needs to be increased dramatically and that primarily digital sales channels should be used. The results also indicated that digital labs are currently not widely used in industry and are becoming increasingly important in education. Digital labs are seen as very useful for teaching and training. Important for sustainability is the revenue stream, which was evaluated in detail. The majority of respondents see a paid service as useful, provided there is "real added value." A positive surprise was the feedback to pay an amount for a digital lab provider. What also became clear, however, is that a marketplace provider must offer the customer clear benefits, such as easier usability, support, accelerate processes and make services easier to identify. One ethical discussion that is affected by this is who should pay for the course content (university, state, or student). But again, this needs to be considered in context and in relation to the benefits. Finally, industry respondents also indicated a willingness to share labs in the network, which is a good indicator of the sustainability of the offering.

A further finding which needs to be addressed is trust. Trust is addressed several times during this paper and is understood as the success component. Establishing trust in a platform is, as shown, not an easy task and must be at the heart of every element. Today, evaluation systems for the quality and reliability of the transaction partners [20] and provider protection (verification of users or insurance) are used. The authors believe that a wide-ranging system should be introduced. On one hand, lab environments are very costly, and on the other hand important transactions (lectures) depend on reliability. A trust mode, in which each transaction is evaluated as being above, equal or below expectations, with far-reaching evaluation dimensions and an appropriate visualization system would help to solve this problem. Within logistics processes, performance indicators such as reliability, responsiveness, agility, costs, and asset management efficiency are used to evaluate transactions [73]. Social network analysis, for example, could be used as a visualization system to identify key players in a network at an early stage and, if necessary, to initiate measures to ensure the sustainability of the network.

Finally, to give another perspective, a different approach of a feasibility study is discussed. A publicly funded feasibility study [5] in Germany evaluated the use of an 
(inter)national education platform for higher education and lifelong learning. The goal is similar to what we addressed in this paper, to create a platform for online education and academic learning. Generally, it is assumed that the demand for online education is constantly growing and that students are willing to pay for the education platform. However, the approach does not pursue the transfer of practical knowledge through labs, as explained in this paper. The exciting thing is that a classical business model is used for the feasibility of the university platform. In direct comparison to the innovative and sustainable multi-sided platform, the classic model differs in (1) creating teaching and learning content, (2) the financing model and (3) the staffing requirements. (1) Teaching and learning content is created in-house and requires the development, maintenance and updating of the content and the licensing of the content. (2) The model calculation is based on a financing requirement of 44.5 million euros over six years, with the financing requirement being covered from the seventh year onwards. (3) The staff planning anticipates an increase to 127 internal employees and 670 external tutors/lecturers by the sixth year. This feasibility study shows the advantages of the sharing economy and the benefits of a multi-sided platform as a business model for digital labs. The lab supplier provides the content itself in the best possible way and in relation to the demands of the buyer; the marketplace itself only has a supportive/advisory role. Furthermore, the business model supports the scaling effect for the user. The financial requirements of the marketplace are much lower, as it is possible to concentrate on core competencies. Platform, organizational and operating costs are comparable, but the internal and external staffing requirements are significantly lower.

\section{Conclusion and outlook}

This paper has addressed the problem of online education for STEM subjects. Lab exercises to gain practical experience and hands-on knowledge play an important role in the education of future engineers and scientists. Digital labs can be used to gain this experience online. However, the sharing of digital labs is currently still insufficient. This paper addresses this problem using DSRM process model in which a multi-sided platform for online exchange of digital labs between suppliers and buyers was established as an artifact. A literature review was conducted to design and develop the success criteria for a sustainable business model and to create a multi-sided platform for digital labs. The literature review included BMD, BMFs, BMTs, and multi-sided platforms. The analysis of the BMD could provide information on whether a definition is necessary and which components are required for a BMD. It can be summarized that a research-related BMD is required and in addition the functionalist view of a BMF should be established. The literature on BMFs helped to identify the different approaches to represent the relationship/hierarchical structure between the elements. For a platform model, it also turned out that the Platform Canvas is the right complement for the BMC. The functionalist view of the business models is combined in the BMT. In these, the scaling property of the multi-sided platform was found to be a criterion for the sustainability of the digital lab business model. The multi-sided platform is tailored to the needs and sustainability of the buyer and the supplier. Based on the theoretical 
construct, the findings of the literature were demonstrated towards a case study for lab sharing. For this purpose, the feasibility of the concept for digital labs was first examined. Subsequently, the business model was defined and the functionalist view was elaborated. The functionalist view comprises the Platform Canvas and the BMC. Three evaluations were then conducted to evaluate the established DSRM artifact. First, experiences from the serious game industry were compared with those of the labs on the supplier side. Next, 21 industry respondents and 93 students were surveyed about their intentions to use a digital labs platform. The findings from literature, practical experience and evaluation were then discussed in terms of success criteria for a sustainable business model and functional requirements for a multi-sided platform for digital labs. The concept proved to be coherent and targeted. The next step is to put it into practice to gain knowledge and experience. This will provide more detailed insight into the community, further elaborate buyer and supplier demand, clarify dependencies more precisely, and put the network of trust to the test. In addition, experience will be gained from later life cycle phases (dynamic and performance) of the multi-sided platform.

\section{Acknowledgement}

This work has been funded by the Federal Ministry of Education and Research (BMBF), Germany under the funding code 16DHB2112. The responsibility for the content of this publication lies with the authors.

\section{References}

[1] N. Beutin, Share Economy 2017: The New Business Model. [Online]. Available: http://www.pwc.de/share-economy (accessed: Oct. 9 2020).

[2] M. L. Weitzman, The share economy: Conquering stagflation. Cambridge, Mass.: Harvard Univ. Press, 1984.

[3] P. Goudin, Ed., The Cost of Non-Europe in the Sharing Economy: Economic, Social and Legal Challenges and Opportunities. Brussels: European Parliamentary Research Service, 2016.

[4] F. Boons and N. Bocken, "Towards a sharing economy - Innovating ecologies of business models," Technological Forecasting and Social Change, vol. 137, pp. 40-52, 2018, https://doi.org/10.1016/j.techfore.2018.06.031

[5] U. Schmid, V. Zimmermann, B. Baeßler, and K. Freitag, "Machbarkeitsstudie Für Eine (Inter-)Nationale Plattform Für Die Hochschullehre," Hochschulforum Digitalisierung beim Stifterverband für die Deutsche Wissenschaft e.V., 2018.

[6] A. Pfeiffer and D. Uckelmann, "Open Digital Lab for You - Laboratory-based learning scenarios in education, research and qualification," in 2019 5th Experiment International Conference (exp.at'19), Funchal (Madeira Island), Portugal, 2019, pp. 36-41. https://doi.org/10. 1109/expat.2019.8876560

[7] S. Upadhya, A. Selvaggio, T. R. Ortelt, J. Grodotzki, and E. A. Tekkaya, "Development of a Remote Tube Bending Lab to Illustrate Springback and Determine Process Limits," in 
Paper-A Multi-Sided Platform to Activate the Sharing of Digital Labs

REV2019, 16th International Conference on Remote Engineering and Virtual Instrumentation, B.M.S.College of Engineering, Bengaluru, India, 2019, pp. 83-95. https://doi.org/1 0.1007/978-3-030-23162-0 10

[8] J. G. Zubía and G. Alves, Eds., Using Remote Labs in Education: Two Little Ducks in Remote Experimentation. Bilbao: University of Deusto, 2011. Accessed: Jan. 232019. [Online]. Available: http://www.deusto-publicaciones.es/deusto/pdfs/otraspub/otraspub01 . $\mathrm{pdf}$

[9] G. Romagnoli, G. Esposito, A. Rizzi, F. Zammori, M. Bertolini, and D. Uckelmann, "Lab Networks in Engineering Education: A Proposed Structure for Organizing Information," Int. J. Onl. Eng., vol. 16, no. 05, p. 41, 2020, https://doi.org/10.3991/ijoe.v16i05.11891

[10] R. Heradio, L. de La Torre, D. Galan, F. J. Cabrerizo, E. Herrera-Viedma, and S. Dormido, "Virtual and remote labs in education: A bibliometric analysis," Computers \& Education, vol. 98, pp. 14-38, 2016, https://doi.org/10.1016/j.compedu.2016.03.010

[11] M. Tawfik et al., "Laboratory as a Service (LaaS): a Novel Paradigm for Developing and Implementing Modular Remote Laboratories," Int. J. Onl. Eng., vol. 10, no. 4, p. 13, 2014, https://doi.org/10.3991/ijoe.v10i4.3654

[12] T. I. Eikaas, C. Schmid, B. A. Foss, and D. Gillet, "A Global Remote Laboratory Experimentation Network and the Experiment Service Provider Business Model and Plans," MIC, vol. 24, no. 3, pp. 159-168, 2003, https://doi.org/10.4173/mic.2003.3.2

[13] R. H. Coase, "The Nature of the Firm," Economica, vol. 4, no. 16, pp. 386-405, 1937, https://doi.org/10.1111/j.1468-0335.1937.tb00002.x

[14] R. Amit and C. Zott, "Value creation in E-business," Strat. Mgmt. J., vol. 22, 6-7, pp. 493520, 2001, https://doi.org/10.1002/smj.187

[15] D. Tapscott, D. Ticoll, and A. Lowy, Digital capital: Harnessing the power of business webs. Boston: Harvard Business School Press, 2000. https://doi.org/10.1145/341836.336231

[16] N. Abdelkafi, C. Raasch, A. Roth, and R. Srinivasan, "Multi-sided platforms," Elec. Markets, vol. 29, no. 4, pp. 553-559, 2019, https://doi.org/10.1007/s12525-019-00385-4

[17] A. Osterwalder, "The Business Model Ontology - A Proposition in a Design Science Approach," PhD Thesis, Université de Lausanne, Lausanne, 2004. Accessed: Aug. 142019.

[18] O. E. Williamson, The economic institutions of capitalism: Firms, markets, relational contracting. New York, NY: Free Press, 1987. [Online]. Available: http://www.loc.gov/catdir/ bios/simon051/87011901.html

[19] J. Baalsrud Hauge, V. Kammerlohr, B. Göbl, and H. Duin, "Influence of Trust Factors on Shared Laboratory Resources in a Distributed Environment," in PRO-VE 2019, 2019, pp. 624-634. https://doi.org/10.1007/978-3-030-28464-0_55

[20] D. Schallmo, A. Rusnjak, J. Anzengruber, T. Werani, and M. Jünger, Eds., Digitale Transformation von Geschäftsmodellen: Grundlagen, Instrumente und Best Practices. Wiesbaden: Springer Fachmedien, 2017. https://doi.org/10.1007/978-3-658-12388-8

[21] G. Esposito, D. Mezzogori, D. Reverberi, G. Romagnoli, M. Ustenko, and F. Zammori, "Non-Traditional Labs and Lab Network Initiatives: A Review," Int. J. Onl. Eng., vol. 17, no. 05, p. 4, 2021, https://doi.org/10.3991/ijoe.v17i05.20991

[22] K. Peffers, T. Tuunanen, M. A. Rothenberger, and S. Chatterjee, "A Design Science Research Methodology for Information Systems Research," Journal of Management Information Systems, vol. 24, no. 3, pp. 45-77, 2007, https://doi.org/10.2753/mis0742-12222 $\underline{40302}$

[23] D. Tranfield, D. Denyer, and P. Smart, "Towards a Methodology for Developing EvidenceInformed Management Knowledge by Means of Systematic Review," Br J Management, vol. 14, no. 3, pp. 207-222, 2003, https://doi.org/10.1111/1467-8551.00375 
[24] F. Lang, "Insurance Research," Journal of Marketing, vol. 12, no. 1, pp. 66-71, 1947, https://doi.org/10.1177/002224294701200108

[25] A. B. Jensen, "Do we need one business model definition?," pp. 61-84, 2014, https://doi.org/10.5278/ojs.jbm.v1i1.705

[26] P. Timmers, "Business Models for Electronic Markets: European Commission, DirectorateGeneral III," Elec. Markets, vol. 8, no. 2, pp. 3-8, 1998, https://doi.org/10.1080/ 10196789800000016

[27] C. Zott, R. Amit, and L. Massa, "The Business Model: Recent Developments and Future Research," Journal of Management, vol. 37, no. 4, pp. 1019-1042, 2011, https://doi.org/10.1177/0149206311406265

[28] B. W. Wirtz, Electronic Business, 3rd ed. Wiesbaden: Springer Gabler, 2010. [Online]. Available: http://www.springer.com/

[29] M. W. Johnson, C. M. Christensen, and H. Kagermann, "Reinventing Your Business Model," Harvard Business Review, December 2008, pp. 1-12, 2008. http://radio.shabanali.com/reinventing-your-business-model.pdf

[30] H. Chesbrough, "Business Model Innovation: Opportunities and Barriers," Long Range Planning, vol. 43, 2-3, pp. 354-363, 2010, https://doi.org/10.1016/j.lrp.2009.07.010

[31] H. Chesbrough and R. S. Rosenbloom, "The role of the business model in capturing value from innovation: evidence from Xerox Corporation's technology spin-off companies," Industrial and Corporate Change, vol. 11, no. 3, pp. 529-555, 2002, https://doi.org/10.1093/ icc/11.3.529

[32] R. Casadesus-Masanell and J. E. Ricart, "From Strategy to Business Models and onto Tactics," Long Range Planning, vol. 43, 2-3, pp. 195-215, 2010, https://doi.org/10.1016/j. lrp.2010.01.004

[33] C. Baden-Fuller and S. Haefliger, "Business Models and Technological Innovation," Long Range Planning, vol. 46, no. 6, pp. 419-426, 2013, https://doi.org/10.1016/j.lrp.2013.08.023

[34] E. Fielt, "Conceptualising Business Models: Definitions, Frameworks and Classifications," pp. 85-105, 2014, https://doi.org/10.5278/ojs.jbm.v1i1.706

[35] D. J. Teece, "Business Models, Business Strategy and Innovation," Long Range Planning, vol. 43, 2-3, pp. 172-194, 2010, https://doi.org/10.1016/j.lrp.2009.07.003

[36] M. Yrjölä, "Value Creation Challenges in Multichannel Retail Business Models," pp. 89104, 2014, https://doi.org/10.5278/OJS.JBM.V2I1.725

[37] A. Osterwalder, Y. Pigneur, and T. Clark, Business model generation: A handbook for visionaries, game changers, and challengers. Hoboken NJ: Wiley, 2010. https://doi.org/10. $1111 / j .1540-5885.2012 .009772 . x$

[38] B. W. Wirtz, A. Pistoia, S. Ullrich, and V. Göttel, "Business Models: Origin, Development and Future Research Perspectives," Long Range Planning, vol. 49, no. 1, pp. 36-54, 2016, https://doi.org/10.1016/j.lrp.2015.04.001

[39] M. Morris, M. Schindehutte, and J. Allen, "The entrepreneur's business model: toward a unified perspective," Journal of Business Research, vol. 58, no. 6, pp. 726-735, 2005, https://doi.org/10.1016/j.jbusres.2003.11.001

[40] M. Lund and C. Nielsen, "The Evolution of Network-based Business Models Illustrated Through the Case Study of an Entrepreneurship Project," pp. 105-121, 2014, https://doi org/10.5278/ojs.jbm.v2i1.720

[41] K. Sorri, M. Seppänen, K. Still, and K. Valkokari, "Business Model Innovation with Platform Canvas," pp. 1-13, 2019, https://doi.org/10.5278/OJS.JBM.V7I2.1966

[42] P. Weill and M. R. Vitale, Place to space: Migrating to eBusiness models. Boston, Mass.: Harvard Business School Press, 2001. 
[43] P. Di Tullio, D. Valentinetti, and M. Rea, "Integrating the Business Model puzzle: A systematic Literature Review," International Journal of Business Research and Management (IJBRM), Vol 9 No 1 (2018), pp. 1-47, 2018.

[44] J. E. Cuc, "Trends of Business Model Research," 2020, https://doi.org/10.5278/ ojs.jbm.v7i5.2981

[45] C. Zott and R. Amit, "Business Model Design: An Activity System Perspective," Long Range Planning, vol. 43, 2-3, pp. 216-226, 2010, https://doi.org/10.1016/j.lrp.2009.07.004

[46] B. Wirtz and P. Daiser, "Business Model Innovation: An Integrative Conceptual Framework," pp. 14-34, 2017, https://doi.org/10.5278/ojs.jbm.v5i1.1923

[47] O. Gassmann, K. Frankenberger, and M. Csik, The business model navigator: 55 models that will revolutionise your business. Harlow, England, London, New York, Boston, San Francisco: Pearson, 2014.

[48] J. E. Cuc and A. Miina, "Classifying the Business Model from a Strategic and Innovation Perspective,” pp. 15-18, 2018, https://doi.org/10.5278/ojs.jbm.v6i2.2455

[49] D. Lüttgens and K. Diener, "Business Model Patterns Used as a Tool for Creating (new) Innovative Business Models," pp. 19-36, 2017, https://doi.org/10.5278/ojs.jbm.v4i3.1877

[50] C.-J. Petri, "Using an innovative price model to leverage the business model - The case of price model innovation in the largest Swedish taxi company," pp. 56-70, 2014, https://doi.org/10.5278/OJS.JBM.V2I1.723

[51] S. Lambert, "The Importance of Classification to Business Model Research," pp. 49-61, 2015, https://doi.org/10.5278/ojs.jbm.v3i1.1045

[52] L. M. Applegate, E-Business Models: Making Sense of the Internet Business Landscape. In Information Technology and the New Enterprise: Future Models for Managers. [Online]. Available: https://slideplayer.com/slide/4739523/ (accessed: Aug. 19 2020).

[53] M. Rappa, Managing the Digital Enterprise: BUSINESS MODELS ON THE WEB. [Online]. Available: http://digitalenterprise.org/models/models.html (accessed: Jan. 25 2019).

[54] A. Afuah and C. L. Tucci, Internet business models and strategies: Text and cases, 2nd ed. Boston: McGraw-Hill Higher Education, 2001.

[55] M. W. Johnson, Seizing the White Space: Business Model Innovation for Growth and Renewal. Boston: Harvard Business Review Press, 2010. [Online]. Available: https://ebook central.proquest.com/lib/gbv/detail.action?docID $=5181935$

[56] M. Lund and C. Nielsen, "The Concept of Business Model Scalability," pp. 1-18, 2018, https://doi.org/10.5278/OJS.JBM.V6I1.2235

[57] H. W. Chesbrough, Open business models: How to thrive in the new innovation landscape, 1st ed.: Harvard Business Review Press, 2006.

[58] A. Chakravarty, A. Kumar, and R. Grewal, "Customer Orientation Structure for InternetBased Business-to-Business Platform Firms," Journal of Marketing, vol. 78, no. 5, pp. 123, 2014, https://doi.org/10.1509/jm.12.0442

[59] D. P. McIntyre and A. Srinivasan, "Networks, platforms, and strategy: Emerging views and next steps," Strat. Mgmt. J., vol. 38, no. 1, pp. 141-160, 2017, https://doi.org/10.1002/smj .2596

[60] A. Gawer and M. A. Cusumano, "Industry Platforms and Ecosystem Innovation," J Prod Innov Manag, vol. 31, no. 3, pp. 417-433, 2014, https://doi.org/10.1111/jpim.12105

[61] Y. Zhao, S. von Delft, A. Morgan-Thomas, and T. Buck, "The evolution of platform business models: Exploring competitive battles in the world of platforms," Long Range Planning, Vol 53 No 4 (2019), p. 101892, 2019, https://doi.org/10.1016/j.lrp.2019.101892 
[62] European Commission, The Sharing Economy. [Online]. Available: https://www.academia.edu/9481688/Business Innovation Observatory The Sharing Economy Accessibility Based Business Models for Peer-to-Peer Markets (accessed: Dec. 20 2019).

[63] T. R. Eisenmann, G. Parker, and M. W. van Alstyne, "Strategies for Two-Sided Markets," Harvard Business Review, Vol. October, 2006, pp. 1-12, 2006. [Online]. Available: https://ssrn.com/abstract=2409276

[64] S. Behrendt, C. Henseling, and G. Scholl, Eds., Digitale Kultur des Teilens: Mit Sharing nachhaltiger Wirtschaften. Wiesbaden: Springer Fachmedien, 2019. https://doi.org/10.1007/ 978-3-658-21435-7

[65] C. Henseling, C. Hobelsberger, C. Flick, and S. Behrendt, Nachhaltige Entwicklungsperspektiven für Geschäftsmodelle des Peer-to-Peer Sharing: PeerSharing Arbeitsbericht 6. Berlin, 2018. Accessed: Dec. 9 2019. https://doi.org/10.1007/978-3-658-21435-7 7

[66] M. Heikkilä, S. Solaimani, A. Soudunsaari, M. Hakanen, L. Kuivaniemi, and M. Suoranta, "Performance Estimation of Networked Business Models: Case Study on a Finnish eHealth Service Project," pp. 71-88, 2014, https://doi.org/10.5278/ojs.jbm.v2i1.724

[67] B. Otto and M. Jarke, "Designing a multi-sided data platform: findings from the International Data Spaces case," Elec. Markets, vol. 29, no. 4, pp. 561-580, 2019, https://doi.org/ $10.1007 / \mathrm{s} 12525-019-00362-\mathrm{x}$

[68] A. Sihn-Weber and F. Fischler, CSR und Klimawandel: Unternehmenspotenziale und Chancen einer nachhaltigen und klimaschonenden Wirtschaftstransformation, 1st ed. Köln: Cologne Business School, 2020. https://doi.org/10.1007/978-3-662-59748-4

[69] K.-M. Ahrend, Geschäftsmodell Nachhaltigkeit: Ökologische und soziale Innovationen als unternehmerische Chance. Berlin, Heidelberg: Springer Berlin Heidelberg, 2016. [Online]. Available: https://doi.org/10.1007/978-3-662-58717-1 3

[70] T. Haertel, C. Terkowsky, and S. Dany, Eds., Hochschullehre \& Industrie 4.0: Herausforderungen - Lösungen - Perspektiven. Bielefeld: W. Bertelsmann Verlag, 2019.

[71] T. A. Singh and K. Singh, Business Models of Sharing Economy. [Online]. Available: https://www.slideshare.net/abhishekthakur1291421/business-models-of-sharing-economy (accessed: Apr. 14 2020).

[72] J. Baalsrud Hauge et al., "Business models for Serious Games developers - transition from a product centric to a service centric approach," IJSG, vol. 1, no. 1, 2014, https://doi.org/ 10.17083/ijsg.v1i1.10

[73] APICS, Supply Chain Operations Reference (SCOR) model. [Online]. Available: https://www.apics.org/docs/default-source/scc-non-research/apicsscc scor quick reference guide.pdf (accessed: 11.01.21).

\section{Authors}

Valentin Kammerlohr is a PhD student in the Department of Systems and Technology in the College of Business at Auburn University. His research interests include Internet of Things / Industry 4.0, business models especially of the sharing economy, trust and digital labs. He is currently working as a research associate at the University of Applied Sciences (HFT) Stuttgart in the research project DigiLab4U. Between 2012 and 2018, he worked as Solution Sales (IBM Sales-Pro talent program) and Consultant at IBM in the field of Internet of Things and Workplace Services for Industry and Au- 
tomotive. He holds a Master's degree in Business \& Process Management (Master@IBM) and a Bachelor's degree in Business Information Systems from Reutlingen University.

Dieter Uckelmann studied Mechanical Engineering at TU Braunschweig and received his doctorate at the University of Bremen in the Faculty of Production Engineering. Between 2005 and 2012 he has established and managed the LogDynamics Lab at the University of Bremen. Since 2012 he is a professor for Information Logistics at Hochschule für Technik (HFT) Stuttgart. Additionally, since 2017 he is a visiting professor at the University of Parma, where he co-supervises two $\mathrm{PhD}$ candidates. He has been a visiting researcher at the University of Cambridge (UK, 2009) and University of Parma (Italy, 2016). The focus of his research work is in the field of the Internet of Things, Industry 4.0, and Smart Buildings, the value of information, as well as on labbased research and education. Since 2018, he coordinates the project DigiLab4U and works in other research projects on Smart Public Buildings and industrial sensor/augmented reality applications. Furthermore, he is co-editor of the "International Journal of RF-Technologies: Research and Applications". Prior to his academic career, he has been working in different management positions for several IT companies (email: dieter.uckelmann@hft-stuttgart.de).

Jannicke Baalsrud Hauge is head of the BIBA GamingLAB and works as a senior researcher at Bremer Institut für Produktion und Logistik (BIBA) Bremen, Germany. Furthermore, she is associate professor for production logistics and program director for the master programs on sustainable production developments (2y program) and on applied logistics (1y program) at KTH, Sweden. From 2001 to 2003 she worked as a research scientist at the University of Bremen, with her main responsibility being the functional architecture of an e-commerce software. 2003 she joined BIBA, where she is responsible for the BIBA Gaming LAB as well as coordination of the BIBA contribution in several national and international projects in the field of Serious Gaming as well as ICT in production and supply chain networks and CPS. Besides supervising BSc, Master and PhD students, she is teaching SG application development, re-engineering, decision making and supply chain risk management. Her main topics are on development of SG and simulation applications, development of GBL concepts, requirements engineering (IT solutions for logistics, CPS and SG), process analysis and business modelling. Jannicke is member of several boards and has authored $250+$ papers.

Article submitted 2021-07-01. Resubmitted 2021-08-09. Final acceptance 2021-08-10. Final version published as submitted by the authors. 